Finance and Economics Discussion Series Divisions of Research \& Statistics and Monetary Affairs Federal Reserve Board, Washington, D.C.

\title{
Macroeconomic Volatility, Predictability and Uncertainty in the Great Moderation: Evidence From the Survey of Professional Forecasters
}

\section{Sean D. Campbell}

2004-52

NOTE: Staff working papers in the Finance and Economics Discussion Series (FEDS) are preliminary materials circulated to stimulate discussion and critical comment. The analysis and conclusions set forth are those of the authors and do not indicate concurrence by other members of the research staff or the Board of Governors. References in publications to the Finance and Economics Discussion Series (other than acknowledgement) should be cleared with the author(s) to protect the tentative character of these papers. 


\title{
Macroeconomic Volatility, Predictability and Uncertainty in the Great Moderation: Evidence From the Survey of Professional Forecasters
}

\author{
Sean D. Campbell \\ Board of Governors of the Federal Reserve System
}

September, 2004

\begin{abstract}
An emerging and influential literature finds a large and significant decline in macroeconomic volatility since the middle of the 1980's. In this paper, I examine the extent to which the decline in annual and quarterly real output volatility since the onset of this period of Great Moderation can be attributed to changes in macroeconomic uncertainty and macroeconomic predictability. I use point forecasts of future real output growth from the Survey of Professional Forecasters (SPF) between 1969 and 2003 as a proxy for the predictable component of real output growth. The results indicate that declining predictability has played a significant role in the Great Moderation. Prior to the Great Moderation, professional forecasts explained roughly 30 percent of the variance in output growth. Post-moderation, the predictive ability of professional forecasts quickly vanished. This decline in predictability implies that interpreting the decline in the volatility of output shocks identified from a fixed parameter autoregressive model overstates the decline in macroeconomic uncertainty by between $20-40$ percent. I also examine forecasts of the probability of a decline in real output from the SPF. Consistent with the findings from the point forecast data, these probability forecasts indicate that the decline in macroeconomic uncertainty as measured from an autoregressive model is overstated. While both the average probability of a decline in output and the uncertainty surrounding future declines in output computed from an autoregressive model decrease sharply after the mid-1980's, the SPF probability forecasts exhibit no such decrease. I assess the economic significance of the overstatement in the decline of macroeconomic uncertainty in terms of its effects on forecasts of the future equity premium. These results indicate that using the decline in the total volatility of real output growth along with the standard CCAPM model overstates the decline in the future equity premium by roughly 20 percent.
\end{abstract}

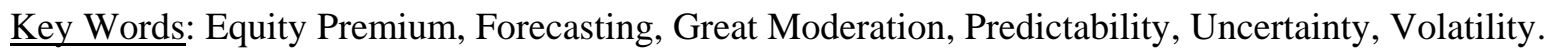

Acknowledgments: I would like to thank Dean Croushore, Mike Gibson, Peter Hansen, Matthew Pritsker, David Weil, Hao Zhou and participants at the NBER Summer Institute Workshop on Forecasting and Empirical Methods for Macroeconomics and Finance for their comments on this research. The views in this paper are solely the responsibility of the author and should not be interpreted as reflecting the views of the Board of Governors of the Federal Reserve System or of any person associated with the Federal Reserve System. 


\section{Introduction}

In the last five years, an emerging body of macroeconomic research has documented a considerable decline in U.S. macroeconomic volatility beginning in the mid-1980's. A descriptive literature, beginning with Kim and Nelson (1999), McConnell and Perez-Quiros (2000) and Blanchard and Simon (2001), estimates that since 1984 macroeconomic volatility, broadly defined, has declined by roughly 40 percent. A recent contribution by Stock and Watson (2003) suggests that this "Great Moderation” is a robust feature of the macroeconomic landscape shared across a range of different sectors within the U.S. economy as well as across international borders.

While these studies clearly document a sharp decline in total macroeconomic volatility, the provenance of this decline is less well-documented. One potential source of the decline could be a reduction in macroeconomic uncertainty, as measured by the volatility of unanticipated macroeconomic shocks. Alternatively, however, the decline could stem from a decline in the volatility of the predictable component of macroeconomic activity. A decline in the volatility of either the unpredictable or predictable component of real activity would result in a decline in total macroeconomic volatility. Understanding how these two sources contribute to the observed moderation in macroeconomic volatility is important for evaluating the welfare implications of the decline as well as its potential effects on other aspects of the macroeconomy. Asset pricing models, for example, predict that the long-run excess return on the stock market depends on the amount of macroeconomic uncertainty faced by investors but is insensitive to the extent of macroeconomic predictability. Accordingly, the likely effects of the Great Moderation on the stock market hinge on whether it is primarily a consequence of a decline in macroeconomic uncertainty or predictability.

In this paper, I decompose the volatility of U.S. real output growth into a component that is related to the volatility of the predictable component of real output growth and a component that is due to the volatility of unanticipated macroeconomic shocks. Specifically, I identify the predictable component of real output growth from the survey responses of professional forecasters contained in the Survey of Professional Forecasters (SPF) between 1969 and 2003. Using these point forecasts, I am able to trace the source of the decline in macroeconomic volatility. Previous work documenting the decline in macroeconomic volatility has typically relied on autoregressive, time series models to distinguish the predictable from the unpredictable component of real output growth. The SPF forecast data are better suited to distinguishing the predictable from the unpredictable component of real output growth for two reasons. First, the SPF forecast data represent the real time, actual expectations of economic participants who are actively engaged in tracking the future path of the macroeconomy. Second, I show that over the 
sample period, the SPF forecasts are of either similar or superior quality relative to those generated from an autoregressive model. Consequently, the SPF forecast data provide a more realistic estimate of actual expected future growth and are more informative about the roles of changing uncertainty and predictability in the Great Moderation.

The SPF forecast data indicate that both macroeconomic uncertainty and predictability have exhibited a substantial decline since 1984. In the case of predictability, the information content of growth forecasts has deteriorated sharply relative to a benchmark autoregressive model. Before 1984 forecasts constructed from an autoregressive model for real output growth were considerably less accurate than those elicited from professional forecasters. After 1984, the accuracy of the autoregressive and SPF forecasts are very similar. Consequently, attributing the entire decline in real output volatility to a reduction in uncertainty tends to overstate the size of the reduction in macroeconomic uncertainty. A portion of the decline in real output volatility is accounted for by the decline in real output predictability and not real output uncertainty. When uncertainty is measured using a root mean squared error (RMSE) criteria, I find that failing to account for the decline in predictability overstates the decline in quarterly real output growth uncertainty by 20 percent. Examining annual real output growth forecasts suggests an even larger overstatement ranging from between 25 percent to 62 percent.

Aside from real output growth point forecasts, the SPF contains another source of information on how macroeconomic uncertainty and predictability have changed since the mid-1980's. Namely, the SPF reports the probability of a decline in real output in the quarter following the survey. Unlike the point forecasts of real output growth, these probabilities constitute distribution forecasts. As a result these forecasts are richer than pure point forecasts as they provide information on both the likelihood of future real output declines and on the level of uncertainty surrounding future declines. Importantly, the measure of uncertainty provided by these forecasts represents a purely ex ante assessment of the risk of future recessions. As such, the measure of uncertainty provided by these forecasts does not rely on the use of ex post data in its construction. Consistent with the findings from SPF point forecasts, when the SPF probability forecasts are compared to those from an autoregressive model with a single structural break in the variance of growth shocks, the evidence suggests that the SPF forecasts are both rational and encompass the autoregressive probability forecasts. In stark contrast to the probabilities computed from the autoregressive model, the SPF probabilities indicate no large or statistically significant decrease in either the probability of a decline in output nor in the uncertainty surrounding this event. Accordingly, when uncertainty is measured relative to a future decline in real output these data provide considerably less evidence in favor of a large decline in macroeconomic uncertainty. 
The remainder of this paper is organized as follows. Section 2 discusses the SPF point forecasts as well as the autoregressive model typically employed for forecasting real output growth. I document the information content of the SPF forecasts relative to autoregressive forecasts over the 1969-2003 period and discuss the implications for volatility measurement. Section 3 documents the role that declining predictability has played in contributing to the decline in real output volatility. In particular, I examine the extent to which ignoring the role of declining predictability overstates the decline in real output uncertainty. Section 4 discusses the SPF probability forecasts and the probability forecasts generated from an autoregressive model. I investigate the information content of the SPF relative to the autoregressive forecasts. I then address the evidence in favor of a Great Moderation in both the probability and uncertainty of future recessions. Section 5 interprets the size of the overstatement in the decline of macroeconomic uncertainty in terms of measuring the effects of the change in real output uncertainty on the long-run equity premium of the U.S. stock market within the context of the CCAPM asset pricing model. Section 6 concludes and discusses directions for future research.

\section{Identifying the Predictable and Unpredictable Components of Real output Growth: Autoregressive Forecasts vs. SPF Forecasts}

Identifying the extent to which macroeconomic uncertainty, in general, and real output growth uncertainty, in particular, has declined since the mid-1980's requires an estimate of the unpredictable component of real output growth. Consider the following fundamental decomposition of output growth and its variance,

$$
\begin{array}{ccc}
y_{t, t+h} & = & E\left(y_{t, t+h} \mid \mathbf{\Omega}_{t}\right)+e_{t, t+h}^{u} \\
\operatorname{Var}\left(y_{t, t+h}\right) & = & \operatorname{Var}\left(E\left(y_{t, t+h} \mid \Omega_{t}\right)\right)+E\left(\operatorname{Var}\left(e_{t, t+h}^{u}\right)\right)
\end{array},
$$

where $y_{t, t+h}$ represents h-period output growth, $E\left(y_{t, t+h} \mid \Omega_{t}\right)$ represents the conditional expectation of output growth based on the full time $t$ information set, $\Omega_{t}$, and $e_{t}^{u}$ is the unpredictable component of real output growth In this way, the variance of real output growth can be decomposed into the variance of its predictable and unpredictable components. A reduction in the variance of output growth that arises from a change in $E\left(\operatorname{Var}\left(e_{t, t+h}^{u}\right)\right)$ is considered a reduction in uncertainty. A reduction in the variance of output 
growth that arises from a reduction in $\operatorname{Var}\left(E\left(y_{t, t+h} \mid \Omega_{t}\right)\right.$ is considered a reduction in predictability. ${ }^{1}$ As discussed in the introduction, reductions in macroeconomic volatility that arise from a reduction in uncertainty could have vastly different implications than those that arise from a reduction in predictability.

\subsection{Autoregressive Models for the Predictable Component of Real output Growth}

In econometric studies of the decline in macroeconomic volatility, the predictable component of output growth is often estimated using a time-series or other econometric forecasting model to construct estimates of the conditional mean. These estimates are then used, along with the data, to identify the unpredictable component of output growth. In the context of the recent Great Moderation literature, the vast majority of researchers have focused on autoregressive specifications in modeling the conditional mean of output growth. ${ }^{2}$ In the case of a first-order autoregressive specification (henceforth, AR(1)) the econometric model takes the form,

$$
y_{t, t+h}=\alpha+\rho y_{t-h, t}+\sigma \varepsilon_{t, t+h},
$$

where $\rho$ is the parameter that governs the persistence of real output growth, $\alpha$ determines the mean of real output growth (holding $\rho$ fixed) and $\sigma$ represents the volatility of real output growth shocks. Much of the evidence in favor of the Great Moderation comes from examining the estimated residuals,

$$
e_{t, t+h}=y_{t, t+h}-\hat{\alpha}-\hat{\rho} y_{t-h, t},
$$

where $\hat{\alpha}$ and $\hat{\rho}$ are estimated parameters. McConnell and Perez-Quiros (2000), for example find a large and significant decline after 1984 in the volatility of residuals from an AR(1) model in the case of quarterly real output growth between 1953:2 and 1999:2. Stock and Watson (2002) find a similar decline in the volatility of residuals from an AR(4) model in the case of (overlapping) annual real output growth. Moreover, both sets of authors also find that the only compelling source of structural change within these autoregressive models is in the volatility of growth shocks, $\sigma$. Both McConnell and Perez-Quiros (2000) as well as Stock and Watson (2002) test for structural change in both the mean and persistence parameters

\footnotetext{
${ }^{1}$ The term predictability here is synonymous with the phrase, "variance of the predictable component”. Later, the term predictability will be used in the context of $R^{2}$. The context will make clear which sense of predictability is being referred to.

${ }^{2}$ Kim, Nelson and Piger (2001), McConnell and Perez-Quiros (2000), Stock and Watson $(2002,2003)$ and Stock and Watson (2003) use autoregressive specifications in modeling real output growth.
} 
of their autoregressive specifications and find no evidence in favor of structural change in either of these parameters.

These findings clearly document, in a rigorous fashion, that the volatility of real output growth has declined precipitously since 1984. These studies, however, are less informative as to whether the volatility decline is due to changes in macroeconomic uncertainty or predictability. If the residuals from the AR(1) specification are identified with unanticipated real output growth shocks, then all of the decline in macroeconomic volatility is due to a decline in the volatility of the unpredictable component of real output growth. Identifying, however, the residuals from the AR(1) model with the unpredictable component of real output growth requires an assumption that no other variables available to economic participants besides lagged growth rates are useful for forecasting future growth. Specifically, this assumption equates $e_{t, t+h}$ with $e_{t, t+h}^{u}$.

There are reasons to suspect that this identifying assumption may not be satisfied. Autoregressive models describe $E\left(y_{t, t+h} \mid Y_{t-h, t}\right)$ which may be highly informative for understanding how well past output growth forecasts future output growth, but may be a noisy proxy for $E\left(y_{t, t+h} \mid \Omega_{t}\right)$ for at least two reasons. First, the information set consisting of lagged growth rates is clearly much smaller than the information set available to investors, firms and other economic agents attempting to forecast future real activity. The considerable amount of time and energy spent on forecasting future growth by government agencies, investors and firms would itself suggest that future growth is affected by more than just its own past. Second, the dependence of future growth on its own past may well exhibit important non-linearities. Regime-switching models of the type considered by Hamilton (1989) and others indicate that nonlinearities are an important feature of the U.S. business cycle, suggesting that concerns about the restrictive nature of linear models, autoregressive or otherwise, may not be completely unwarranted.

\subsection{Nonparametric Measures of the Predictable Component of Real Output Forecasts: The Survey of Professional Forecasters}

In this paper, I use an estimate of the conditional expectation of real output growth, $E\left(y_{t, t+h} \mid \Omega_{t}\right)$, which is not derived from an econometric model. I make use of real-time forecasts elicited from professional forecasters in the Survey of Professional Forecasters (SPF). The forecasts are for both quarterly ( $h=1)$ and annual ( $h=4$ ) real output growth. The forecasts are observed over the period between 1969:1 and 2003:2 in the case of the quarterly forecast horizon and between 1971:2 and 2002:4 
in the case of the annual forecast horizon. ${ }^{3}$ The Survey of Professional Forecasters is the oldest quarterly survey of macroeconomic forecasters in the United States. The survey was originally conducted by the American Statistical Association and the National Bureau of Economic Research. Since 1990, the survey has been administered by the Federal Reserve Bank of Philadelphia. Each quarter, the survey asks professional forecasters from the academic, government and private sector to forecast a variety of macroeconomic aggregates ranging from consumer prices and corporate profits to aggregate investment and real output. ${ }^{4}$

The use of the SPF in measuring the expectations of economic agents is not novel. The forecasts contained in the SPF have been used repeatedly as measures of conditional expectations and many authors find that these forecasts dominate those from econometric, time-series models. In particular, Hafer and Hein (1985), find that SPF forecasts for inflation outperform predictions from interest rate based models or other econometric time-series models. Su and Su (1975) also find that the SPF forecasts are more accurate than those generated from econometric time series models. Apart from the previous evidence suggesting the superiority of the SPF forecasts, using these forecasts to identify the unpredictable component of real output growth, $e_{t, t+h}^{u}$, has several additional advantages over the method that employs an autoregressive model. First, these forecasts are conditioned on the full information set of professionals who allocate a considerable amount of time and other resources to forecasting future real activity. As such, these forecasts are constructed from a rich and evolving information set which likely incorporates any changes in the predictive power of different leading macroeconomic indicators over time. Second, these forecasts are not constrained to adhere to any pre-specified rule about how changes in the information set influence the forecast. Accordingly, these forecasts are flexible enough to incorporate the effects of any non-linearities or changes in the importance of different leading indicators that are relevant for future growth expectations.

\subsection{The Information Content of SPF and Autoregressive Forecasts: 1969-2003}

Before analyzing the information content of the autoregressive and SPF forecasts it is important to recognize the differences in timing between the two forecasts. The autoregressive forecasts are constructed using final revised real output data. This vintage of output data is employed in constructing

\footnotetext{
${ }^{3}$ Throughout the paper the notation yyyy:q is used to denote the qth quarter of year yyyy.

${ }^{4}$ Croushore (1993), provides a detailed description of the SPF and surveys the academic literature as well as the practical uses the survey has served since its inception in 1968.
} 
the autoregressive forecasts for two reasons. First, a main goal of this paper is to examine how the use of actual, real time forecasts from the SPF effects the findings of previous research. Accordingly, a comparison to autoregressive forecasts based on final revised data is relevant for comparing the results obtained from the SPF to the previous work of Kim and Nelson (1999), Kim, Nelson and Piger (2003), McConnell and Perez-Quiros (2000) and Stock and Watson (2002, 2003) all of whom employ final revised data in the estimation of their respective autoregressive models. Second, since the predictand of interest is clearly final revised output growth because it provides the best measure of the state of the economy at any point in time, the use of lagged final revised output growth as a predictor endows the autoregressive forecast with a considerable amount of foresight. In this way, the autoregressive forecasts can be thought of as forecasts provided by an omniscient forecaster who chooses to rely only on the previous history of output growth in tracking the future path of the macroeconomy. ${ }^{5}$

The timing of the SPF forecasts is as follows. The survey is mailed out to participants at the end of the first month following each quarter. The first quarter survey, for example, is typically mailed out near the end of January. Surveys are due back a few weeks after they are sent out to participants. Given the nature of the survey, it is not possible to determine exactly when the surveys were completed by the participants. While the timing of the autoregressive and SPF forecasts clearly do not coincide it is important to recognize that the difference in timing has been constant throughout the entire sample. Much of this paper is concerned with how the behavior of the SPF and autoregressive forecasts change pre- and post-1984. As a result, it is not clear that a constant difference in the timing of the two forecasts will obfuscate inferences made about how the behavior of these forecasts have changed since the Great Moderation.

In order to gauge how informative the SPF forecasts are relative to autoregressive forecasts, I compare the predictive accuracy and relative information content of these two forecasts over the 19692003 period. Both quarterly ( $h=1)$ and annual $(h=4)$ growth forecasts are examined. I focus on the case of the AR(1) model because of its prevalence in the literature and because the difference between the predictions of an AR(1) model and a more general AR(p) model are minor in both quarterly and annual (non-overlapping) real output growth data. Specifically, I estimate the parameters of the model,

$$
y_{t, t+h}=\alpha+\rho y_{t-h, t}+\varepsilon_{t, t+h}
$$

\footnotetext{
${ }^{5}$ One might argue that a more realistic comparison would compare the performance of a forecast using real-time real output growth with those from the SPF. This, however, assumes that revisions to output are themselves completely unforecastable. Aruoba (2003), however, finds evidence that revisions to output are indeed forecastable. A comparison of a "real-time" autoregressive forecast to the SPF would then require a fully specified forecasting model of the revisions process. While clearly of interest, the construction of a "real-time" autoregressive forecast is beyond the scope of this paper.
} 
using the full sample of data. As discussed previously, I do not allow for any time variation in either $\alpha$ or $\rho$ due to the substantial research that fails to find any significant evidence of time variation in these parameters using both similar data and a similar sample. Furthermore, the AR(1) model is a simple and parsimonious model that is widely used among macroeconomists for forecasting purposes. Once the model is augmented to allow for breaks in the mean and the persistence parameter the relevance of the model as a benchmark forecasting model comes into question. In particular, the effects of "look ahead bias” that arise from conditioning the model on the observed data may make such a model more of a descriptive device rather than a realistic forecasting model.

Measures of predictability and forecast accuracy are constructed using the full sample estimates in the case of the AR(1) and in the case of the SPF forecast I treat the median of all recorded forecasts within a period as that period's representative forecast. Use of the median forecast follows a long line of research using survey data on expectations. While other methods of aggregating forecasts such as the mean or a trimmed mean could also be employed, I focus on the use of the median because of its robustness properties and because of its prevalence in the previous literature.

Predictability and forecast accuracy measures are computed over the entire sample, 1969-2003 as well as two subsamples. The subsamples are chosen to coincide with the dating of the Great Moderation. While different authors disagree on the exact dating of the Great Moderation, most authors agree that the large decline in volatility began during 1984. McConnell and Perez-Quiros (2000) estimate a break date of 1984:1 using quarterly real output growth data between 1953:2 through 1999:2. Using the same methods as these authors but a slightly different sample, 1969:1 through 2003:2, I estimate a break date of 1984:3. Since the SPF forecast data are only available over this latter sample, I use a break date of 1984:3 in dating the Great Moderation.

Before discussing the forecasting and predictability measures it is useful to examine the time series of real output growth and the two sets of growth forecasts. The top panel of Figure 1 provides a time-series plot of the SPF and AR(1) quarterly growth forecasts while the bottom panel plots the realized quarterly real output growth over the sample period. A line indicating the dating of the Great Moderation is presented in both panels. The most noticeable feature in the top panel of Figure 1 is the increased variability of the SPF forecast relative to the AR(1) forecast before the Great Moderation. Before 1984, there are several instances in which the SPF provides a more pointed forecast than does the autoregressive model. Perhaps the most striking example of this occurs in 1980, when the SPF forecast captured nearly all of the decline in real output as opposed to the AR(1) which still forecasted positive (though meager) economic growth. After 1984, the difference between the two sets of forecasts is much less noticeable. 
The SPF forecasts are still somewhat more variable than the AR(1) but much less so. This difference in variability pre- and post-moderation will turn out to have important consequences for the predictability measures that follow.

Consider the $R^{2}$ measure of predictability. Specifically, consider the $R^{2}$ of h-step ahead forecasts from both the AR(1) and the SPF. While other measures of predictability may also be relevant for gauging the relative accuracy of the AR(1) versus SPF forecasts, the h-step ahead $R^{2}$ is an important and widely reported metric of predictability. Recall that the h-step ahead $R^{2}$ is defined as,

$$
R_{h}^{2}=1-\frac{\sum_{t=1}^{T} e_{t, t+h}^{2}}{\sum_{t=1}^{T}\left(y_{t, t+h}-\bar{y}\right)^{2}},
$$

where $e_{t, t+h}$ is the forecast residual from either the AR(1) or the SPF forecast. Over the period 19692003, the $R^{2}$ of the quarterly SPF forecasts is 22.3 percent as compared to only 6.5 percent for the AR(1) forecast. ${ }^{6}$ While these estimates suggest that the SPF forecasts are considerably more accurate than those generated from the $\mathrm{AR}(1)$, examining the one-step ahead $R^{2}$ pre- and post-moderation reveals that the considerable advantage of the SPF over the AR(1) forecasts quickly deteriorated after 1984. Prior to 1984:3, the SPF forecast exhibited an $R^{2}$ of 29.95 percent with observed real output growth as compared to only 7.4 percent for the AR(1) model. After the onset of the Great Moderation, the $R^{2}$ of the AR(1) model falls slightly to 4.7 percent but the predictive accuracy of the SPF is completely eliminated. The sample estimate of the $R^{2}$ between observed and forecasted growth is -4.26 percent, indicating that professional forecasters' ability to predict future growth is dominated by the (ex post) mean growth rate. ${ }^{7}$

The results are similar when comparing the $R^{2}$ of annual real output forecasts. The sample $R^{2}$ of SPF annual real output forecasts is 21.7 percent as compared to 0.7 percent for the AR(1) model over the entire sample period. Before the large decline in macroeconomic volatility, SPF forecasts were considerably more accurate than the AR(1) model. The $R^{2}$ between the actual and forecasted growth rates is 28.28 percent in the case of the SPF forecasts as compared with a point estimate of -4.1 percent in

\footnotetext{
${ }^{6}$ At this point it is worth noting that use of the full-sample estimates in constructing the AR(1) forecast residuals maximizes the in-sample $R^{2}$. Hence, the population $R^{2}$ of the AR(1) model is certainly lower than 6.5 percent.

${ }^{7}$ Recall that the point estimate of $R^{2}$ is not constrained to lie in the unit interval since the forecast errors are not constrained to have a sample mean of zero over either subsample, or even over the entire sample in the case of the SPF forecasts.
} 
the case of the AR(1). After 1984:3, the roles of the SPF and AR(1) forecasts are reversed with the SPF forecasts exhibiting a negative point estimate of -16.53 percent and the predictive accuracy of the AR(1) model rising to 6.4 percent. The evidence from both these annual forecasts and the quarterly forecasts indicate that apart from a decline in volatility, the Great Moderation also ushered in a period of reduced forecastabality.

While these $R^{2}$ estimates provide a useful measure of the accuracy of the SPF and AR(1) forecasts, a more complete analysis of these forecasts requires an analysis of their relative merits in forecasting output. In particular, it is important to know whether the AR(1) forecasts are extraneous when compared with the SPF forecasts. A finding that the AR(1) forecasts are completely irrelevant when compared with the SPF forecasts would indicate that measuring the predictable and unpredictable components of output growth with the AR(1) model is problematic. Alternatively, a finding that the SPF forecasts are redundant in the presence of the AR(1) forecasts would cast serious doubt on the interpretation of the SPF forecasts as "optimal forecasts" of future growth. In order to examine the relative predictive power of the two forecasts, I estimate a forecast encompassing regression of the form,

$$
y_{t, t+h}=\beta_{0}+\beta_{A R} f_{t, t+h \mid t}^{A R}+\beta_{S P F} f_{t, t+h \mid t}^{S P F}+\beta_{1} D_{1984: 3}+\beta_{A R, 1}\left(D_{1984: 3} \times f_{t, t+h \mid t}^{A R}\right)+\beta_{S P F, 1}\left(D_{1984: 3} \times f_{t, t+h \mid t}^{S P F}\right)+\eta_{t, t+h}, \text { (6) }
$$

where $f_{t, t+h \mid t}^{A R}=\hat{\alpha}+\hat{\rho} y_{t-h, t}$ and $f_{t, t+h \mid t}^{S P F}$ are forecasts for either quarterly or annual real output growth. I also allow for the possibility that the relative information content of the two forecasts may differ before and after the Great Moderation. Accordingly, the specification includes a full set of interactions with $D_{1984: 3}$ which is a dummy variable taking the value one after 1984:3 and zero otherwise. Under the null hypothesis that the SPF forecasts are both rational, in the sense that they provide unbiased forecasts, and optimal, in the sense that no other information is relevant for forecasting future growth the following parameter values in the encompassing regression, $\left(\beta_{0}, \beta_{A R}, \beta_{S P F}, \beta_{1}, \beta_{A R, 1}, \beta_{S P F, 1}\right)=(0,0,1,0,0,0)$, would be expected. I present estimates of the encompassing regression along with three Wald tests for both quarterly and annual forecasts in Table 1. The first Wald statistic tests the joint hypothesis that the SPF forecasts are rational and completely encompass the autoregressive forecasts $\left(\beta_{0}, \beta_{A R}, \beta_{S P F}, \beta_{1}, \beta_{A R, 1}, \beta_{S P F, 1}\right)=(0,0,1,0,0,0)$. The second statistic tests the hypothesis that the SPF forecasts encompass the $\operatorname{AR}(1)$ forecasts prior to the great moderation, $\left(\beta_{0}, \beta_{A R}, \beta_{S P F}\right)=(0,0,1)$. The third Wald statistic examines the hypothesis that there is no difference in the parameters pre- and post-moderation, $\beta_{1}=\beta_{A R, 1}=\beta_{S P F, 1}=0$. 
The first column of Table 1 presents the results for the quarterly growth forecasts. The full sample results provide some evidence that the SPF forecasts are rational and fully encompass the AR(1) forecasts. The Wald test of this hypothesis is rejected at the 10 percent level but not at the 5 percent level. The results provide more convincing evidence, however, that the SPF forecasts encompass the AR(1) forecasts before the onset of the Great Moderation. Over this period, the sample estimate of the coefficient on the SPF forecasts is nearly one (0.99) and the coefficients on the constant and AR(1) forecast are both small and insignificant. The Wald test fails to reject the hypothesis that the SPF forecasts dominate the AR(1) forecasts over the first half of the sample at any conventional significance level. This result can be interpreted in terms of the plot in Figure 1. Prior to 1984, the SPF forecasts exhibited considerably more variation than those from the AR(1) model. The results of the encompassing regression indicate that the increased variation reflected additional information content rather than noise. Mirroring the results from the previous analysis of $R^{2}$, the superiority of the SPF forecasts relative to the AR(1) model deteriorates in the second half of the sample. While a Wald test of the restriction of no difference in parameters pre- and post-moderation fails to find any evidence in favor of a change in the parameters, the point estimates indicate that during the period of the Great Moderation, the SPF forecasts and $\operatorname{AR}(1)$ both contribute equally to forecasting future growth. ${ }^{8}$

The pattern in the results for annual forecasts are similar to those from the quarterly forecasts. The hypothesis that the SPF forecasts dominate the AR(1) forecasts over the entire sample is less credible, however, for these annual forecasts. The Wald test rejects this hypothesis at the 5 percent level but not the 1 percent level. Examining the full set of results makes it clear that this rejection stems from the erosion of the information content of the SPF forecasts relative to the AR(1) post-moderation. Before 1984:3, there is considerable evidence that annual SPF forecasts dominate the AR(1) forecasts. The associated Wald test is unable to reject this hypothesis at any conventional significance level. Also, the point estimates are similar to those from the quarterly forecast data. The coefficient on the SPF forecasts is very close to unity (1.08) and precisely measured. The coefficients on the constant and the AR(1) forecasts are larger than in the case of the quarterly forecasts but are indistinguishable from zero. Furthermore, the loading on the AR(1) forecast is estimated to be negative, suggesting a serious deficiency in the AR(1) forecasts prior to the Great Moderation. The estimates from the encompassing model in the second half of the sample indicate that the quality of the annual SPF forecasts eroded even more precipitously than the quarterly forecasts. The point estimates show that the SPF forecasts contain

\footnotetext{
${ }^{8}$ The point estimate of the loading on the SPF and AR(1) forecasts are 0.50 and 0.64 , respectively, and the constant term is very small,-0.1, after 1984:3.
} 
little information for forecasting future growth, $\hat{\beta}_{S P F}=0.17$. This conclusion, however, should be tempered by the fact that the encompassing results also indicate that the $\mathrm{AR}(1)$ forecast is far from an optimal forecast. The estimated loading on the AR(1) forecast is well in excess of unity (2.60) and the forecast is badly biased in the sense that the estimated constant term is large (-5.0). Viewed in this light, the annual forecast encompassing results suggest that neither the SPF or the AR(1) model provides a particularly informative forecast for future annual growth during the Great Moderation.

Taken as a whole, the forecast encompassing results provide convincing evidence that SPF forecasts provide a more accurate representation of expected future growth than do forecasts from the AR(1) model. Prior to the Great Moderation the encompassing tests for both quarterly and annual forecasts indicate that SPF forecasts dominate those from the AR(1). As a result, using the AR(1) model to identify the predictable and unpredictable component of real output growth attributes some portion of the predictable component of output growth to the unpredictable component. After the Great Moderation, the informational advantage of professional forecasters over the AR(1) model declines sharply. In the case of quarterly forecasts, the encompassing tests suggest that the SPF forecasts are comparable with those from the AR(1). In the case of the annual forecasts, the empirical properties of both sets of forecasts are at odds with the notion of being measures of conditional expectations. In any event, there is reason to prefer the SPF forecasts to the AR(1) forecasts when measuring the predictable component of real output growth both pre- and post-moderation. Unlike the AR(1) forecasts, the SPF forecasts are real time expectations elicited before the realization of real output. As such, the SPF forecasts are not subject to any model selection or estimation biases that arise in the context of estimated models. ${ }^{9}$ Moreover, these forecasts provide the best available estimate of what can be reasonably considered to be known about the future path of the macroeconomy at the time the surveys were conducted.

\section{The Decline in Real Output Forecastability and Uncertainty}

The coincidence of the Great Moderation in real output volatility and in the predictive ability of professional forecasters implies that at least part of the decline in real output volatility is due to declining predictability rather than declining uncertainty. The previous section documents that SPF forecasts of real output growth at both the annual and quarterly frequency have experienced a large decline in

\footnotetext{
${ }^{9}$ Rolling or recursive estimation of the AR(1) model would provide a means of lessening the degree of this problem. The underlying problem, however, is unescapable. Regardless of the estimation method, choices concerning lag length, the set of covariates and other specification issues are likely to be influenced by the observed sample path of output growth. It is in this sense, that the SPF forecasts provide an alternative which is estimation free.
} 
predictability since the beginning of the Great Moderation. Recall, that the $R^{2}$ of the SPF quarterly real output growth forecasts declined from 29.9 percent between 1969:1 and 1984:3 to a negative point estimate -4 percent between 1984:4 and 2003:2. Compare this decline in the $R^{2}$ of the SPF forecasts to the change in $R^{2}$ that would occur if real output growth were adequately modeled as an AR(1) with only a one time change in the variance of output shocks as assumed, for example, in the work of McConnell and Perez-Quiros (2000). Recall that in the case of an AR(1), the population $R^{2}$ is simply $\rho^{2}$ so that a single change in the variance of real output growth shocks would imply no loss in predictability, as measured by $R^{2}$, whatsoever. ${ }^{10}$ This feature of the AR(1) model further implies that all of the decline in the volatility of real output growth would be attributed to a reduction in uncertainty leaving no scope for a reduction in predictability.

Accounting for the effects of declining real output growth predictability can have important consequences for measuring the change in real output uncertainty. In order to make this point concrete, assume that the relevant measure of uncertainty is the forecast's mean squared error (MSE) which is consistent with the measurement framework adopted in equation (1). One convenient way of expressing forecast MSE is, $M S E=E\left[\operatorname{Var}\left(e_{t, t+h}^{u}\right)\right]=E\left[\left(y_{t, t+h}-f_{t, t+h \mid t}\right)^{2}\right]=\operatorname{Var}\left(y_{t, t+h}\right) *\left(1-R^{2}\right)$,

where $f_{t, t+h \mid t}$ is the real output forecast with corresponding $R^{2}$. Accordingly, the ratio of forecast MSE across two subperiods is simply, $\frac{M S E_{1}}{M S E_{0}}=\frac{\operatorname{Var}_{1}\left(y_{t, t+h}\right)}{\operatorname{Var}_{0}\left(y_{t, t+h}\right)} \frac{\left(1-R_{1}^{2}\right)}{\left(1-R_{0}^{2}\right)}$. In the context of an autoregressive model for real output growth with fixed mean and persistence parameters, the ratio of the forecast MSE is simply, $\frac{M S E_{1}}{M S E_{0}}=\frac{\operatorname{Var}^{1}\left(y_{t, t+h}\right)}{\operatorname{Var}^{0}\left(y_{t, t+h}\right)}$. In the case of the SPF quarterly growth forecasts, the substantial decline in $R^{2}$ indicates that measuring the decline in macroeconomic uncertainty from a pure autoregressive model

\footnotetext{
${ }^{10}$ One might contend that structural changes in $\rho$ coinciding with the change in the volatility of real output growth shocks could have occurred which would result in a change in predictability. While true, the evidence presented by McConnell and Perez-Quiros (2000) as well as Stock and Watson (2002) provide evidence against this hypothesis. Tests of structural change in the mean and persistence of real output growth fail to find any evidence in favor of a structural break.
} 
for output growth overstates the decline by, $\frac{\left(1-R_{1}^{2}\right)}{\left(1-R_{0}^{2}\right)}=1.485,48.5$ percent in the case of MSE and by 21.9

percent in the case of RMSE (root mean squared error).

I report the RMSE from the AR(1) forecast and the SPF forecasts across the two subperiods, 1969:1 - 1984:3 and 1984:4 - 2002:2 in Table 2. In all calculations, RMSE is defined as,

$$
R M S E=\sqrt{\frac{1}{T} \sum_{t=1}^{T} e_{t, t+h}^{2}},
$$

where $e_{t, t+h}$ is the forecast error from either the AR(1) model, $e_{t, t+h}=y_{t+h, t}-\hat{\alpha}-\hat{\rho} y_{t-h, t}$, or the SPF forecasts, $e_{t}=y_{t+h, t}-f_{t, t+h \mid t}$. The annual RMSE calculations are shown for each quarter separately and averaged across all quarters in Table 2. Annual forecasts made in different quarters are analyzed separately because there is reason to expect that annual forecasts made in different quarters behave differently. Fourth quarter forecasts, for example, coming at the end of the calendar year when many firms, investors and government agencies make plans for the coming year may be made using more time and effort, and may therefore be expected to be more accurate, than forecasts made during other quarters.

The results for forecasts of quarterly real output growth confirm the $R^{2}$ calculations above. As noted previously, during the 1969:1 - 1984:3 subperiod, the SPF forecasts were more accurate than those from the AR(1). In particular, the RMSE of the SPF forecasts was 13 percent smaller than that of the AR(1). After 1984, the forecastability of real output growth eroded relatively quickly. Over the entire 1984:4 - 2002:2 subperiod, the RMSE of the SPF forecasts was 4 percent worse than that of the AR(1) model. This implies that using the AR(1) to measure the change in real output uncertainty, as measured by RMSE, overstates the decline by 20 percent relative to the SPF forecasts (3.98/2.13 vs. 4.58/2.04). Analyzing annual growth forecasts suggest that using the AR(1) model to identify the unpredictable component of real output growth results in an even larger overstatement of the change in macroeconomic uncertainty. The pooled sample of annual growth forecasts indicates that the SPF forecasts were 28 percent more accurate, in the RMSE sense, before 1984 and 20 percent less accurate thereafter. This implies a 36 percent overstatement in the reduction of annual real output RMSE (2.53/1.51 vs. 3.07/ 1.36). The estimates of the overstatement using annual forecast data range from between 25 percent in the case of third quarter annual forecasts to 62 percent in the case of fourth quarter annual forecasts.

The point estimates contained in Table 2 are suggestive but not definitive. In particular, the results contained in Table 2 do not provide a measure of sampling uncertainty to gauge their statistical 
significance. The differences in the change in macroeconomic uncertainty as measured by the SPF and the AR(1) model could simply be a matter of chance. In order to assess the statistical significance of the results contained in Table 2, I specify and estimate a model for the AR(1) and the SPF forecasts that restricts the MSE of both forecasts to be proportional to each other both before and after the Great Moderation. Specifically, the SPF forecasts may have a lower MSE than the AR(1) forecasts, due to the larger information set available to SPF forecasters, across both subperiods but the percentage change in the MSE across the Great Moderation is restricted to be identical across both sets of forecasts. In terms of Table 2, the model implies that $\frac{R M S E_{1}^{S P F}}{R M S E_{0}^{S P F}}=\frac{R M S E_{1}^{A R}}{R M S E_{0}^{A R}}$. The model is specified as,

$$
\begin{array}{rlr}
y_{t, t+h} & =\alpha+\rho y_{t-h, t}+\varepsilon_{t, t+h} \\
e_{t, t+h} & =y_{t, t+h}-f_{t, t+h \mid t} \\
E\left[\left(\varepsilon_{t, t+h}\right)^{2} \mid \Omega_{t}\right] & =\sigma_{0, \varepsilon}^{2}\left(1+\kappa D_{1, t}\right) \\
E\left[\left(e_{t, t+h}\right)^{2} \mid \Omega_{t}\right] & =\sigma_{0, e}^{2}\left(1+\kappa D_{1, t}\right) \\
D_{1, t} & =1\left(t \geq T^{*}\right) \\
T^{*} & =1984: 3
\end{array},
$$

where $y_{t, t+h}$ is the growth in real output and $f_{t, t+h \mid t}$ is the associated forecast from the SPF. The parameter, $\kappa$, measures the reduction in uncertainty post-moderation so that $\frac{R M S E_{1}^{S P F}}{R M S E_{0}^{S P F}}=\frac{R M S E_{1}^{A R}}{R M S E_{0}^{A R}}=1+\kappa$ and represents the single restriction of the model. The model is estimated by GMM using both the quarterly and annual forecast data that was used in the construction of Table 2. The model contains five parameters, $\left(\alpha, \rho, \kappa, \sigma_{0, A R}, \sigma_{0, S P F}\right)$, and was estimated using six moments leaving one degree of overidentification for Hansen's J-statistic. Ultimately, the J-statistic will be used to determine whether or not 
the differences between $\frac{R M S E_{1}^{S P F}}{R M S E_{0}^{S P F}}$ and $\frac{R M S E_{1}^{A R}}{R M S E_{0}^{A R}}$ reported in Table 2 are significant or not.

The model estimates and specification test are contained in Table 3. The estimation results clearly indicate that forecast uncertainty did decline significantly after 1984. Across both quarterly and annual forecast horizons, the estimated decline in RMSE is remarkably consistent, ranging between 46 and 49 percent. The J-statistic, however, indicates that the assumption of an identical proportional decline in forecast uncertainty across the AR(1) and SPF forecasts is at odds with the data. The specification test is rejected at the 3 percent level in the case of the quarterly forecasts and at the 6 percent level in the case of the (pooled) annual forecasts. These results confirm the interpretation given to the point estimates contained in Table 2. Inferences drawn from the AR(1) model lead to an overstatement in the reduction of macroeconomic uncertainty since 1984. The source of the overstatement is the simultaneous decline in predictability. At precisely the time that real output shocks became less volatile, the economy became less predictable. This reduction in predictability has resulted in a smaller decline in uncertainty, as measured by the MSE of SPF forecasts, than would have resulted if there had been no decline in predictability after 1984.

\section{Evidence on the Decline in Real Output Uncertainty from Forecasts of the Probability of a Decline in Real Output}

While the SPF point forecasts analyzed here are a valuable source of information on the predictable component of real output and accordingly also real output uncertainty, they are not the only source of forecast data within the SPF that may be useful for investigating how uncertainty and predictability have changed since the onset of the Great Moderation. In particular, the SPF also elicits forecasts of the distribution of output growth over the following year at the time of the survey and the next calendar year from participants. In principle, these data are an excellent source of information on this topic. Importantly, the spread of these distributions would serve as an excellent proxy for the degree of ex ante uncertainty surrounding output growth. Unfortunately, these distribution forecasts are hampered by a key change in the survey design which dramatically reduces their information content. The predictand was changed in the second quarter of 1981 from nominal output to real output. While the SPF also elicits a distribution forecast for inflation, only the marginal distribution of inflation and output growth are reported making it impossible to convert the nominal distribution forecast to a real distribution forecast or vice-versa. Moreover, quite unfortunately, the change from nominal to real output occurs at 
almost precisely the same time as the Great Moderation ensuring that neither series alone contains enough data both pre- and post- Great Moderation to provide for econometric inference with any reasonable degree of power.

The SPF does, however, contain information on the probability of a decline in real output in the quarter following the survey. Moreover, this question has been included in the survey since its inception. ${ }^{11}$ While most of the Great Moderation literature is concerned with real output growth, this is clearly not unrelated to a decline in real output or a recession. ${ }^{12}$ Recessions provide a different measure of macroeconomic performance that can provide insight into the extent to which macroeconomic volatility and uncertainty have changed since the mid-1980's. Moreover, a key advantage of these data is that they represent distribution forecasts. Accordingly, the level of uncertainty measured by these probability forecasts represents an ex ante assessment of the risk surrounding future recessions. In this way, these forecast data provide an excellent opportunity to learn about how forward-looking assessments of macroeconomic uncertainty have changed since the mid-1980's.

The top panel of Figure 2 contains a time series plot of these probability forecasts along with the probability forecasts computed from a Gaussian AR(1) that allows for a single structural break in the variance of growth shocks in 1984:3. Figure 2 also displays the quarters in which real output growth was negative and quarterly realized output growth rates in the bottom panel. ${ }^{13}$ Both sets of forecasts tend to rise before and during recessions and fall thereafter. The SPF forecasts, however, display considerably more variation. Compared to the AR(1) forecasts, the SPF forecasts tend to rise more just before and decline more just after periods of negative growth. This pattern is especially apparent in the period before the Great Moderation. This pattern is directly in line with the observed pattern in point forecasts from Figure 1. Before the Great Moderation both the SPF point and probability forecasts exhibit considerably more variation than those from the AR(1) model. Post-moderation the SPF probability forecasts still exhibit more variation than those from the AR(1) but to a lesser extent.

\subsection{The Information Content of SPF and Autoregressive Recession Forecasts: 1969-2003}

Before examining how the uncertainty surrounding recessions has changed since the Great

\footnotetext{
${ }^{11}$ The only change in the survey question is that prior to the first quarter of 1992, participants were asked to report the probability of a decline in real GNP. After the first quarter of 1992, participants were asked to report the probability of a decline in real GDP. real output”.

${ }^{12}$ The term recession is being used loosely in this context to be synonymous with the phrase "one quarter decline in

${ }^{13}$ Before the first quarter of 1992 real output is identified with GNP, thereafter it is identified with real GDP.
} 
Moderation, it is important to examine whether the probability forecasts elicited by the SPF represent reasonable proxies for the actual probability of a recession. Following the analysis of the previous section, I compare the information content of the SPF probability forecast with the probability forecast of the Gaussian AR(1) model through an encompassing regression of the form,

$$
1\left(y_{t, t+1}<0\right)=\beta_{0}+\beta_{A R} P_{t}^{A R}+\beta_{S P F} P_{t}^{S P F}+\beta_{1} D_{1984: 3}+\beta_{A R, 1}\left(D_{1984: 3} \times P_{t}^{A R}\right)+\beta_{S P F, 1}\left(D_{1984: 3} \times P_{t}^{S P F}\right)+\eta_{t, t+h},
$$

where $1\left(y_{t, t+1}<0\right)$ indicates the event of a decline in real output over the next quarter, $P_{t}^{S P F}$ represents the median probability of this event as reported in the SPF, $\operatorname{Pr}\left(y_{t, t+1}<0 \mid \Omega_{t}\right), P_{t}^{A R}$ is the probability of a decline in real output over the next quarter computed from the AR(1) model and $D_{1984: 3}$ is a dummy variable that takes the value one after 1984:3. As in the case of real output growth point forecasts, I allow for the possibility of differences in information content in the two probability forecasts pre- and postGreat Moderation. Since I am interested in how the uncertainty surrounding recessions changed before and after the Great Moderation it is important to establish that the SPF probabilities represent rational forecasts during both subperiods. A complication that arises in the estimation of this encompassing regression is that the limited nature of the dependent variable implies that the error term displays heteroskedasticity. In particular, under the null hypothesis that $P_{t}^{S P F}$ is both rational and encompasses the AR(1) forecast, the variance of the error term is simply $P_{t}^{S P F}\left(1-P_{t}^{S P F}\right)$. In order to account for the heteroskedasticity, I impose this null hypothesis and estimate the regression via GLS.

In the top panel of Table 4, I present the results from the encompassing regression. Importantly, the point estimate of $\beta_{S P F}$ is both close to unity (0.95) and rather precisely estimated. Also, the estimates of all other parameters are typically small and imprecisely measured. In terms of magnitude the parameters $\beta_{A R, 1}$ and $\beta_{S P F, 1}$ are somewhat larger though insignificantly different from zero. Furthermore, taking these point estimates at face value would imply roughly equal weights on both the AR(1) and SPF forecasts post-moderation providing little evidence that the AR(1) is preferable to the SPF over this subperiod. The null hypothesis that the SPF probability forecast encompasses the AR(1) forecast and that they are rational can not be rejected at any reasonable significance level. Consequently, the SPF probabilities of a decline in real output present the best opportunity to learn about how uncertainty surrounding the onset of a recession has changed since the mid 1980's. 


\subsection{The Decline in Recession Uncertainty Over the Great Moderation}

Consider the probability, $P_{t}^{S P F}$, of a decline in real output. A natural way to assess the uncertainty surrounding this event is to consider the variance of its distribution $\sigma_{t}^{2}=P_{t}\left(1-P_{t}\right)$. The time series of the standard deviation of this distribution, $\sigma_{t}$, is plotted in the middle panel of Figure 2 . Measures of uncertainty computed from an AR(1) model with a one time break in volatility during 1984:3, $\sqrt{P_{t}^{A R}\left(1-P_{t}^{A R}\right)}$, are also plotted in the same panel of Figure 2. Since real output growth has a positive mean, a simple model in which only the scale of the distribution changes with the onset of the Great Moderation would naturally imply a sharp reduction in the probability of a decline in real output and as long as this probability is less than one-half it would also imply a reduction in the uncertainty surrounding a recession. As Stock and Watson (2003) note “[b]ecause recessions are periods of negative growth, a moderation in output volatility with no change in the mean growth rate implies, in this mechanical sense, shorter recessions and longer expansions”. If the Great Moderation can be reasonably characterized as simply a one-time change in the scale of the distribution of growth shocks then the variance of the distribution of recessions, $\sigma_{t}^{2}$, should exhibit a sharp decline after 1984. In particular, the results from an $\mathrm{AR}(1)$ model for output growth with only a one-time break in the variance of growth shocks would predict a dramatic decline in the long-run probability of a single quarter decline in output from roughly 27 percent pre-moderation to 8 percent thereafter, implying a halving of the standard deviation of the distribution of recessions. Looking at the top panel of Figure 2, it is clear that the probability forecasts computed from the AR(1) exhibit just this type of sharp decrease immediately after 1984:3 while the SPF forecasts do not. Importantly, after 1984, the AR(1) forecasts are typically below those from the SPF.

In Table 5, I present the results from regressing the log of the standard deviation of next quarter's recession on a constant and a post-moderation dummy variable,

$\sqrt{P_{t}^{S P F}\left(1-P_{t}^{S P F}\right)}=\alpha+\left(\alpha_{1984: 3}-\alpha\right) D_{1984: 3}+\eta_{t}$,

along with Newey-West (1987) standard errors. For the sake of comparison, Table 5 also contains results 
for the uncertainty surrounding future recessions as measured by the AR(1) model, $\sqrt{P_{t}^{A R}\left(1-P_{t}^{A R}\right)}$. The results contained in Table 5 are surprising given the findings in Tables 2 and 3. These tables show that both an autoregressive model and the SPF indicate that the variance of the unpredictable component of real output growth has exhibited a sharp reduction since 1984. The results concerning the recession probabilities, however, show no such decline in recession uncertainty. Only a scant and insignificant change in the uncertainty surrounding recessions from 0.36 to 0.34 is exhibited by the SPF probability forecasts. This is strikingly small compared to the halving of the standard deviation that is implied by the parametric AR(1) model. Specifically, the results contained in Table 5 indicate that the measure of uncertainty from an AR(1) model declined precipitously and significantly from 0.44 to 0.28 . One potential explanation for this lack of any significant decline in recession uncertainty is that forecasters learned of the reduction in uncertainty only gradually thereby causing a lag in the SPF uncertainty measure. Looking at Figure 2, it does appear as though uncertainty did decline somewhat after the 1991 recession, but this decline was short-lived as uncertainty has risen to levels at the end of the sample period that are consistent with the level of uncertainty experienced during the most uncertain periods of the 1970's and 1980's. Furthermore, the reduced levels of uncertainty experienced between 1991 through 1999 were still higher than the lowest levels of uncertainty experienced during 1972-1973 and 19761977. As a result, it seems unlikely that adding the possibility of a lag in the break would lead to an improvement in the case for a decline in recession uncertainty post-Great Moderation.

Persistence in the business cycle naturally leads to persistence in the uncertainty surrounding recessions as is evident in Figure 2. Aside from understanding whether the overall level of recession uncertainty has changed since the Great Moderation, it is also of considerable interest to know whether the persistence of shocks to uncertainty has changed. In order to investigate the persistence properties of the SPF uncertainty series, I transform it to a $\log$ uncertainty series, $\log \left(\sqrt{P_{t}^{S P F}\left(1-P_{t}^{S P F}\right)}\right)$, and estimate an AR(1) model that allows for breaks in either the mean or the persistence of the series after 1984:3. Specifically, I estimate the econometric model,

$y_{t}=\alpha+\left(\alpha_{1984: 3}-\alpha\right) D_{1984: 3}+\rho y_{t-1}+\left(\rho_{1984: 3}-\rho\right)\left(D_{1984: 3} \times y_{t-1}\right)+\varepsilon_{t}$, where $y_{t} \equiv \log \left(\sqrt{P_{t}^{S P F}\left(1-P_{t}^{S P F}\right)}\right)$ and $D_{1984: 3}$ is a dummy variable taking the value one after 1984:3. Interestingly, while the point estimate of the change in persistence, $\left(\rho_{1984: 3}-\rho\right)$, suggests a slight decrease in the degree of persistence (-0.16) in uncertainty shocks, the point estimate is measured very 
imprecisely. Accordingly, it is unlikely that either the average level or the persistence of recession uncertainty has changed substantially since the Great Moderation.

It is possible to gain further insight into the lack of change in recession uncertainty by noting that,

$$
\begin{aligned}
\sigma_{t}^{2} & =P_{t}^{S P F}-\left(P_{t}^{S P F}\right)^{2} \\
\bar{\sigma}^{2} & =\bar{P}-\overline{(P P F}-\overline{\left(P^{S P F}\right)^{2}}, \\
\Delta \bar{\sigma}^{2} & =\Delta \bar{P}^{S P F}-\Delta \overline{\left(P^{S P F}\right)^{2}}
\end{aligned}
$$

where $\bar{x}$ represents a sample average and $\Delta$ represents the difference operator. This decomposition attributes average recession uncertainty to two distinct sources. The first source is simply the average probability of a recession, $\bar{P}^{S P F}$, so that as expected a decrease in the average probability of a recession leads to a reduction in uncertainty. ${ }^{14}$ The second source is a measure of the degree to which the probability forecasts are informative or pointed. Since $-\left(P_{t}^{S P F}\right)^{2}$ is concave, its sample average decreases as the distribution of probability forecasts becomes more concentrated at zero and one. Consider for example, a situation in which one recession forecast is always 25 percent and another in which the forecast is zero 75 percent of the time and unity 25 percent of the time. While both forecasts exhibit the same average probability of a recession, clearly there is less uncertainty associated with the second set of forecasts. In this way, the component, $-\left(P_{t}^{S P F}\right)^{2}$, measures the extent to which variation in the probability forecasts contributes to average recession uncertainty.

In the top row of Table 5, I regress the SPF probability of a recession on the Great Moderation dummy variable. For comparison, results for the AR(1) probabilities are reported. These results indicate that since the Great Moderation, the average SPF probability of a recession has decreased somewhat, though insignificantly, from 24 percent to 17 percent. This is in stark contrast to the sharp reduction exhibited by the AR(1) model which is evident from the second row of Table 5 and from glancing at Figure 2. This incongruence between the AR(1) and SPF probability forecasts could be the result of a more subtle change in the distribution of output growth than suggested by a simple change in scale. While the scale of output shocks has clearly been moderated since the Great Moderation, the evidence from the SPF probability forecasts point to the possibility that changes in higher order moments of the

\footnotetext{
${ }^{14}$ As before, this assumes that the average probability of a recession is less than 0.5 .
} 
distribution of real output growth may also be at work. ${ }^{15}$

While the likelihood of a recession has subsided somewhat, the amount of variation in the recession probabilities has simultaneously exhibited an almost exactly offsetting decrease. Looking at Figure 2, it is possible to see how this decomposition matches the historical record. Prior to 1984, the average probability of a recession was slightly higher but the probability of a recession moved considerably as the economy moved through the business cycle. Importantly, the probability forecast from the AR(1) tends to be too high relative to the SPF forecast during non-recessionary periods and too low relative to the SPF forecasts during recessionary periods. Another way of viewing this change in the behavior of the SPF recession probabilities is by examining the behavior of the log odds ratio, $\log \left(\left(P_{t}^{S P F}\right) /\left(1-P_{t}^{S P F}\right)\right) .{ }^{16}$ In Table 5, I present the results from an autoregressive model for the log odds ratio that allows for changes in both its mean and persistence parameters post-moderation. The point estimates indicate that mean log odds ratio declined somewhat, $\left(\alpha_{1984: 3}-\alpha\right)=-0.25$, post-moderation but, at the same time, the persistence of probability shocks declined, $\left(\rho_{1984: 3}-\rho\right)=-0.12$, implying that recession probabilities vary less post-moderation. While the results indicate that neither of these changes are significant, the significance of the change is not relevant for the decomposition. Both the results in Table 5 and the pattern observed in Figure 2 show that after 1984, the average probability of a recession declined slightly but exhibited considerably less persistent variation, rising less before recessions and falling less afterwards. On balance, the offsetting effects of these two changes results in a very small and insignificant change in recession uncertainty after the Great Moderation. This change in the variation of the probability forecasts is in agreement with the results from the previous section on point forecasts. Both the SPF point forecasts of output growth and the recession probability forecasts exhibit considerably less variation after the onset of the Great Moderation. In the case of the probability forecasts, this reduction in variation has directly contributed to the lack of any significant change in the uncertainty surrounding recessions.

\section{Evaluating the Size of the Overstatement in Macroeconomic Uncertainty on Estimates of the}

\footnotetext{
${ }^{15}$ The coefficient of skewness for quarterly output growth is estimated to be 0.07 between 1969:1 and 1984:3 and -0.39 between 1984:4 and 2003:2 which is at least suggestive of this possibility.

${ }^{16}$ I model the log odds ratio instead of the probabilities themselves since the probabilities are both positive and bounded making a symmetric error distribution in the autoregressive representation implausible. Moreover, the linear assumption for the log odds ratio can be reconciled with a logistic probability model. The qualitative features presented for the log odds ratio are identical to those that are obtained from fitting an autoregressive model to the probabilities themselves.
} 


\section{Equity Premium}

The preceding analyses provide evidence that the actual decline in real output uncertainty has been smaller than that suggested by the AR(1) model for output growth. The importance of the magnitude of the overstatement, however, has not been addressed. Determining its economic relevance demands a precise framework for evaluating the consequences of decreased economic uncertainty. In this section, I briefly examine a simple economic model of asset prices and show how its quantitative predictions would change once the overstatement of the decline in macroeconomic uncertainty is taken into account. I focus on the case of asset prices for two reasons. First, asset markets play a central role in the macroeconomy and the link between macroeconomic fundamentals and asset prices represents one of the key questions addressed by modern macroeconomic research. Secondly, some recent research has attempted to link the decline in macroeconomic volatility since the mid-1980's to the behavior of asset prices since the 1990's. In particular, Lettau, Ludvigson and Wachter (2003) have argued that a significant portion of the increase in U.S. asset values since the 1990's can be explained by the events surrounding the Great Moderation.

Their reasoning follows from the predictions of the classic consumption capital asset pricing model (CCAPM). Consider a standard, complete markets economy with a single source of nondiversifiable consumption risk that grows at a stochastic rate, $\Delta \tilde{c}_{t}$, per period. Further, consider a representative agent endowed with iso-elastic utility and coefficient of relative risk aversion, $\gamma$. Finally, consider a stock with a risky investment return, $\tilde{R}_{t}$, and a risk-free bond with certain return $R^{f}$. Within this framework, it is well known (Cochrane, 2001), that the expected equity premium on the stock may be approximated as,

$$
E\left(\tilde{R}_{t+1}-R^{f} \mid \Omega_{t}\right) \approx \gamma \sigma_{t}\left(\Delta \tilde{c}_{t+1}\right) \sigma_{t}\left(\Delta \tilde{R}_{t+1}\right) \rho_{t},
$$

where $\sigma_{t}^{2}\left(x_{t+1}\right)$ represents the conditional variance of $x_{t+1}, \quad \sigma_{t}\left(x_{t+1}\right)=E\left[\left(x_{t+1}-E\left(x_{t+1} \mid \Omega_{t}\right)\right)^{2} \mid \Omega_{t}\right]$, and likewise $\rho_{t}$ represents the conditional correlation between stock returns and undiversifiable consumption growth.

The expression for the equity premium in (14) makes clear the dependence of the equity premium on investors' uncertainty about future consumption and asset returns. Changes in the volatility of the predictable component of either future consumption or asset returns that are unaccompanied by changes in the volatility of their unpredictable components has no effect on the equity premium. Now, consider the effect of a one time decline in the volatility of the uncertain component of consumption growth from 
$\sigma_{0}\left(\Delta \tilde{c}_{t}\right)$ to $\sigma_{1}\left(\Delta \tilde{c}_{t}\right)$ on the equity premium holding the volatility of asset returns, the correlation between consumption and asset returns as well as preferences fixed. Simple calculation yields that this kind of change in macroeconomic uncertainty yields a proportional change in the equity premium of,

$$
E^{1}\left(\tilde{R}_{t}-R^{f}\right)=\kappa E^{0}\left(\tilde{R}_{t}-R^{f}\right)
$$

where the constant of proportionality is simply the ratio of the RMSE of consumption growth, $\kappa=\frac{\sigma_{1}\left(\Delta \tilde{c}_{t}\right)}{\sigma_{0}\left(\Delta \tilde{c}_{t}\right)}$.

Now consider evaluating the likely effects of the Great Moderation on the equity premium. Before doing so, however, note that the equity premium depends on consumption growth uncertainty and that this paper focuses on output growth. While permanent income hypothesis considerations suggest that the two should not coincide empirical evidence suggests that they have. Stock and Watson (2003), for example, document a similar decline in the volatility of consumption growth and real output growth before and after $1984 .{ }^{17}$ In what follows, I simply assume that the trend in consumption growth volatility and that the breakdown between the predictable and unpredictable components of consumption mirror those of output. ${ }^{18}$

If the entire decline in macroeconomic volatility since 1984 is assumed to be the result of declining uncertainty, i.e. a decline in $\sigma_{t}\left(\Delta \tilde{c}_{t+1}\right)$, then estimates of the decline in RMSE identified from the quarterly AR(1) model contained in Table 2 would suggest that the post-1984 equity premium would decline by 55 percent $((1-0.45) * 100)$. The previous results reported in this paper suggest, however, that this results in an overstatement of the likely decline. A portion of the decline in macroeconomic volatility since 1984 is due to declining predictability which is unrelated to declining uncertainty. The results from the SPF forecast data, also contained in Table 2, suggest that uncertainty has only declined by 46 percent ((1-0.54)*100) . Accordingly, making inferences from relying on the drop in total volatility results in a 20 percent overstatement $((1-0.54 / 0.45) * 100)$ of the probable decline in the equity premium.

\footnotetext{
${ }^{17}$ Stock and Watson (2003) report that the ratio of the standard deviation of consumption growth between 1960-1983 to the standard deviation of consumption growth between 1984-2002 to be 0.6. The ratio of non-consumption components of output growth over the same period is roughly 0.74 and the ratio of the volatility of goods production is 0.72 .

${ }^{18}$ The SPF in principle, could be used to examine the properties of the predictable and unpredictable components of real consumption growth. Survey participants, however, were only asked about real consumption expenditures after the third quarter of 1981, making an analysis pre- and post- Great Moderation infeasible.
} 
While a 20 percent overstatement may not seem very large, investment return calculations can be extremely sensitive to assumed rates of return. Consider, the problem of estimating the solvency position of the Social Security system in thirty years time. Whether the assumed equity premium is 5 percent or 6 percent can have large consequences for the future viability of Social Security. To take a more pragmatic example, imagine estimating the amount of time it will take an initial investment to double in size. The Rule of 70 indicates that a 20 percent overstatement of the decline in the rate of return implies a 20 percent overstatement in the amount of time needed to double one's initial investment. ${ }^{19}$ For example, an investor who uses a 5 percent rate of return estimate instead of an estimate of 6 percent will overestimate the amount of time needed to double her initial investment by over two years. These considerations suggest that a 20 percent overstatement in the decline of the equity premium may be important. At least, they suggest that the effect of declining predictability on the decline in total macroeconomic volatility should be accounted for when measuring the decline in macroeconomic uncertainty that has occurred since 1984.

Using annual output growth rates to estimate the decline in macroeconomic volatility leads to an even larger overstatement. Again, Table 2 shows that the ratio of the standard deviation of annual output growth shocks as measured by the AR(1) has declined by 56 percent ((1-0.44)*100) which would result in an estimate of a 56 percent decline in the equity premium. The annual SPF forecast data contained in Table 2, however, suggest that the volatility of the uncertain component of output has only declined by 40 percent $\left((1-0.60)^{*} 100\right)$ since the beginning of the great moderation, implying that the earlier estimate results in a 36 percent $((1-0.60 / 0.44) * 100)$ overstatement in the decline of the equity premium. Estimates of the overstatement using different annual forecasts from different quarters range between 25 percent to 62 percent. These estimates from annual forecast data suggest even more strongly that the postmoderation decline in predictability may be important for interpreting the likely effects of the Great Moderation on the future equity premium.

Finally, these calculations are all based on the results from Table 2 which measure uncertainty using the SPF point forecasts of real output growth. While this is the relevant measure given the simple asset pricing model examined here it is worthwhile to note that the SPF recession probability forecast data indicate no significant change in either the frequency or the degree of uncertainty surrounding recessions. The role of recessions in determining asset prices has recently taken on an ever-growing importance in both the theoretical and empirical asset pricing literature. Theoretical models such as Campbell and

\footnotetext{
${ }^{19}$ The Rule of 70 states that the amount of time needed to double an initial investment that grows at $\mathrm{r} \%$ per year is approximately 70/r.
} 
Cochrane (1999) and empirical work such as Lettau and Ludvigson (2001) which point to countercyclical variation in risk aversion as a key to understanding the size and variability of the equity premium represents a major strand of modern research in asset pricing. If the frequency and uncertainty surrounding recessions is a more important determinant of asset returns than suggested by the standard CCAPM then the calculations provided here may themselves represent an understatement in the size of the overstatement of the likely decline in the equity premium. Providing a quantitative estimate of the future decline in the equity premium that is consistent with these data on the likelihood and uncertainty surrounding future recessions is an interesting goal for future research.

\section{Conclusion}

A wide body of empirical research convincingly shows that macroeconomic volatility has declined substantially since 1984 . This large decline in volatility represents one of the most prominent features of the modern macroeconomic landscape. This paper uses point forecasts of annual and quarterly real output growth from the Survey of Professional Forecasters (SPF), to identify the predictable and unpredictable components of real output growth between 1969-2003. The SPF forecasts reveal that the period of the Great Moderation represents a moderation in volatility, uncertainty, and importantly, predictability. Before 1984, professional forecasters were considerably more adept than a simple autoregressive model at forecasting future growth. After 1984, the two sets of forecasts are roughly comparable. Moreover, the $R^{2}$ of quarterly growth forecasts fell from roughly 30 percent before the Great Moderation to effectively zero thereafter. This decline in the predictability of future real output growth implies that only a portion of the decline in real output volatility has been due to a decline in macroeconomic uncertainty. Using either the decline in raw volatility or the decline in the volatility of growth shocks identified from a fixed parameter AR(1) model overstates the decline in macroeconomic uncertainty by between 20 to 40 percent.

Forecasts of the probability of a recession (i.e. a decline in output) from the SPF provide even more evidence that the decline in macroeconomic uncertainty is overstated by the AR(1) model. While the probability forecasts from an autoregressive model that allows for a one-time decline in the volatility of growth shocks exhibit a sharp decline after 1984, those from the SPF do not. Moreover, the level of uncertainty surrounding future recessions as measured by the variance of the distribution of future recessions shows no sign of significant abatement since the Great Moderation. This lack of any reduction in uncertainty is due to the fact that the average probability of a recession has only decreased slightly in the SPF since 1984 and the fact that the probability of a recession has also varied less across the business 
cycle. To the extent that a reduction in the uncertainty surrounding future recessions is a key benefit of the Great Moderation, these results suggest that the size of the welfare improvement from the volatility decline may not be as large as that predicted by a simple model in which only the scale of macroeconomic shocks have changed.

The importance of the overstatement of the decline in economic uncertainty was considered by evaluating the economic implications of the Great Moderation on the equity premium. It was shown that the overstatement in the decline in macroeconomic uncertainty leads to an overstatement of the likely decline in the equity premium of roughly 20 percent. I argue that the size of this overstatement is itself economically important and may itself be understated to the extent that the role of recessions in determining the equity premium is more important than that suggested by the standard CCAPM.

These findings suggest a variety of interesting directions for future research. The finding that the variance of the unpredictable component of growth shocks has declined while the probability of a decline in output has not brings up a variety of questions concerning other changes in the shape of the distribution of output growth across the Great Moderation. For example, has output growth become more negatively skewed since the Great Moderation? Moreover, are there any economic reasons to suspect that changes in the variance of output growth would also be accompanied by changes in other moments? Also, these findings indicate that in the sense of $R^{2}$, the future path of the macroeconomy has become less predictable. Understanding the underlying sources of this erosion in predictability could itself provide further insights into the reasons behind the Great Moderation itself. 


\section{References}

Aruoba, B. (2003), “Empirical Properties of Data Revisions,” Manuscript, University of Pennsylvania.

Blanchard, O. And Simon J. (2001), “The Long and Large Decline in U.S. Output Volatility,” Brookings Papers on Economic Activity, 1, 135-164.

Campbell J. and Cochrane J. (1999), "By Force of Habit: A Consumption-Based Explanation of Aggregate Stock Market Behavior,” Journal of Political Economy, 107, 205-251.

Cochrane J. (2001), Asset Pricing, Princeton: Princeton University Press.

Croushore D. (1993), “Introducing the Survey of Professional Forecasters,” Federal Reserve Bank of Philadelphia Business Review, Nov/Dec.

Hafer, R.W. and Hein S.E. (1985), “On the Accuracy of Time-Series, Interest Rate and Survey Forecasts of Inflation,” Journal of Business, 58, 377-98.

Hamilton J.D. (1989), “A New Approach to the Economic Analysis of Nonstationary Time Series and the Business Cycle,” Econometrica, 57, 357-384.

Kim, Chang - Jin, and Nelson C.R. (1999), "Has the U.S. Economy Become More Stable? A Bayesian Approach Based on a Markov Switching Model of the Business Cycle,” The Review of Economics and Statistics, 81, 608-616.

Kim, Chang - Jin, Nelson C.R., and Piger J. (1999), “The Less Volatile U.S. Economy: A Bayesian Investigation of Timing, Breadth and Potential Explanations” Manuscript, Board of Governors of the Federal Reserve System.

Lettau M., Ludvigson S., and Wachter J. (2004), “The Declining Equity Premium: What Role Does Declining Macroeconomic Risk Play,” Manuscript, New York University.

Lettau M., and Ludvigson S. (2001), “Consumption, Aggregate Wealth, and Expected Stock Returns,” The Journal of Finance, 56 (3), 815-849.

McConnell, M. and Perez-Quiros G. (2000), "U.S. Output Fluctuations in the United States: What Has Changed Since the Early 1950's,” American Economic Review, 90(5), 1464-1476.

Newey, W., and West K. (1987), “A Simple Positive Semi-Definite, Heteroskedasticity and Autocorrelation Consistent covariance Matrix,” Econometrica, 55, 703-708.

Stock, J.H. and Watson M.W. (1989), "New Indexes of Coincident and Leading Economic Indicators," NBER Macroeconomics Annual 1989, pp. 351-394.

Stock J.H. and Watson M.W. (2002), “Has the Business Cycle Changed And Why?,” NBER Macroeconomics Annual 2002, pp 159-218.

Stock J.H. and Watson M.W. (2003), "Has the Business Cycle Changed: Evidence and Explanations,” 
Manuscript, Harvard University.

Su, V. And Su, J (1975), “An Evaluation of ASA/NBER Business Outlook Survey Forecasts,” Explorations in Economic Research, 2, 588-618. 
Figure 1

Real Output Forecasts and Realized Output

1969:1 - 2003:2
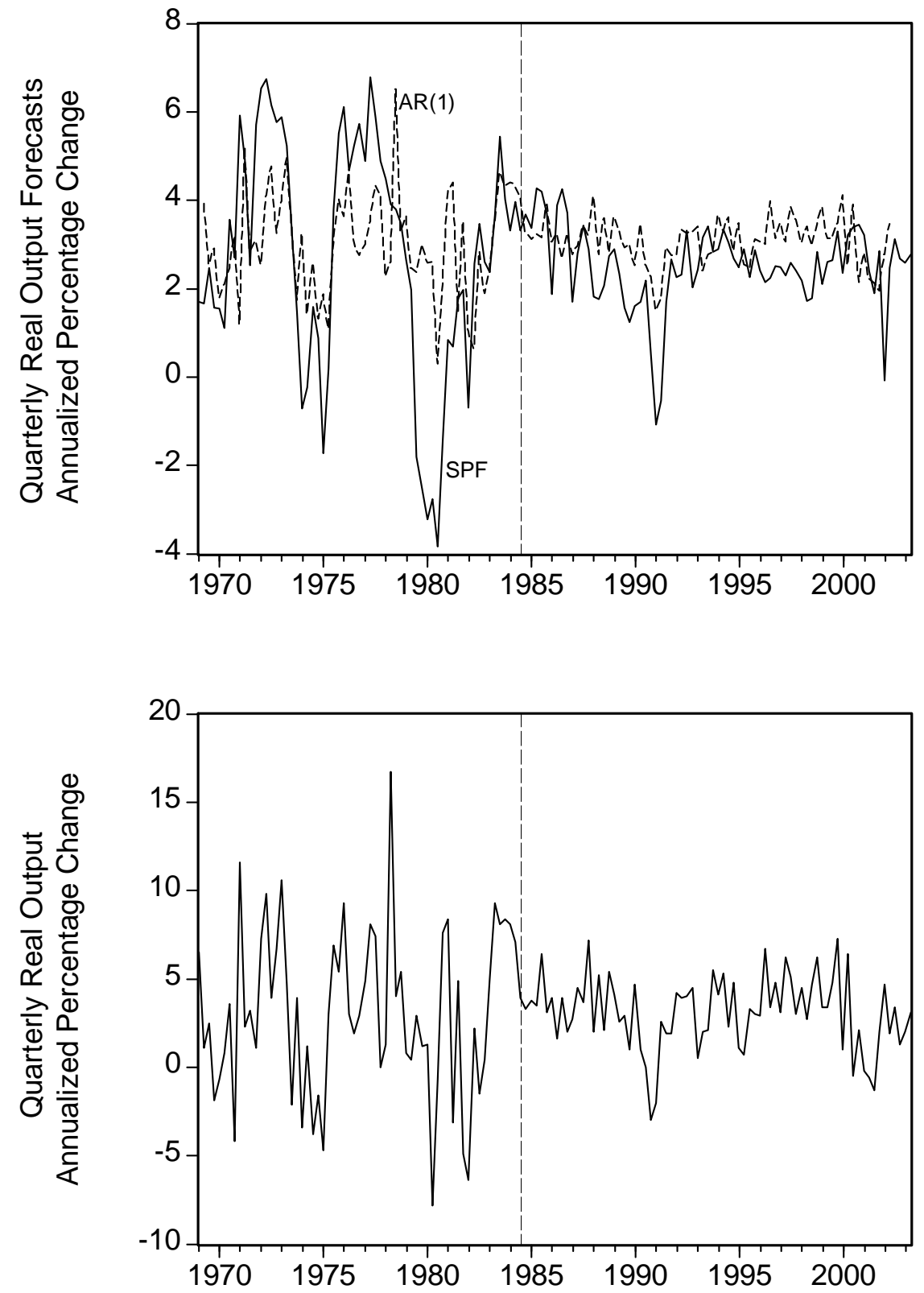

The top panel of this figure displays forecasts of real output growth from both the SPF (solid line) and an AR(1) model (dashed line) 1969:1 - 2003:2. The bottom panel displays realized real output growth (at an annualized rate) 1969:1 - 2003:2. The dashed line in the middle of each panel marks the dating of the Great Moderation, 1984:3. 
Figure 2

SPF vs. AR(1) Probability Forecasts and Recession Uncertainty 1969:1 - 2003:2
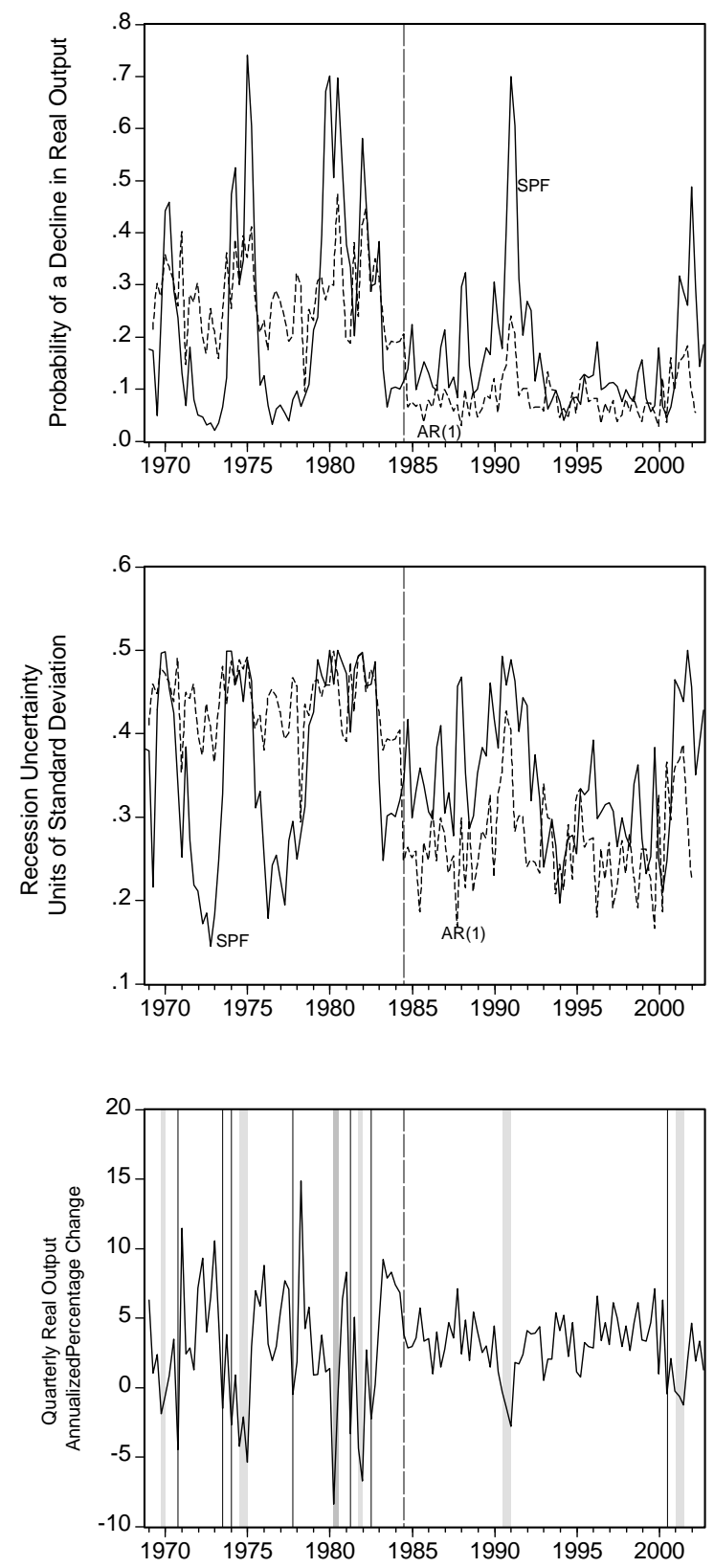

The top panel of this figure displays forecasts of the probability of a decline in real output growth from both the SPF (solid line) and an AR(1) model (dashed line) 1969:1 - 2003:2. The middle panel displays, the uncertainty surrounding a recession (i.e., decline in output) over the next quarter, $\sqrt{P_{t}\left(1-P_{t}\right)}$, from both the SPF and an AR(1) model. The bottom panel displays realized real output growth (at an annualized rate) and highlights quarters of negative growth 1969:1 - 2003:2. The dashed line in the middle of each panel marks the dating of the Great Moderation, 1984:3. 
Table 1

Encompassing Tests

SPF vs. AR(1)

\begin{tabular}{|c|c|c|}
\hline & $\begin{array}{c}\text { Quarterly } \\
\text { 1969:2 - 2002:4 } \\
\end{array}$ & $\begin{array}{c}\text { Annual } \\
1971: 4-2002: 2 \\
\end{array}$ \\
\hline \multicolumn{3}{|l|}{ Parameter Estimates } \\
\hline$\beta_{0}$ & $\begin{array}{c}0.49 \\
(1.22)\end{array}$ & $\begin{array}{l}5.00 \\
(4.0)\end{array}$ \\
\hline$\beta_{A R}$ & $\begin{array}{l}-0.07 \\
(0.41)\end{array}$ & $\begin{array}{l}-1.72 \\
(1.30)\end{array}$ \\
\hline$\beta_{S P F}$ & $\begin{array}{c}0.99 \\
(0.22)\end{array}$ & $\begin{array}{l}1.08 \\
(0.18)\end{array}$ \\
\hline$\beta_{1}$ & $\begin{array}{l}-0.59 \\
(2.13)\end{array}$ & $\begin{array}{l}-10.00 \\
(0.05)\end{array}$ \\
\hline$\beta_{A R, 1}$ & $\begin{array}{c}0.71 \\
(0.69)\end{array}$ & $\begin{array}{c}4.32 \\
(1.70)\end{array}$ \\
\hline$\beta_{S P F, 1}$ & $\begin{array}{l}-0.49 \\
(0.37)\end{array}$ & $\begin{array}{l}-0.91 \\
(0.46)\end{array}$ \\
\hline \multicolumn{3}{|l|}{ Wald Statistics } \\
\hline$\left(\beta_{0}, \beta_{A R}, \beta_{S P F}, \beta_{1}, \beta_{A R, 1}, \beta_{S P F, 1}\right)=(0,0,1,0,0,0)$ & $\begin{array}{l}11.67 \\
(0.07)\end{array}$ & $\begin{array}{l}14.23 \\
(0.03)\end{array}$ \\
\hline$\left(\beta_{0}, \beta_{A R}, \beta_{S P F}\right)=(0,1,0)$ & $\begin{array}{c}0.30 \\
(0.96)\end{array}$ & $\begin{array}{c}0.79 \\
(0.50)\end{array}$ \\
\hline$\left(\beta_{1}, \beta_{A R, 1}, \beta_{S P F, 1}\right)=(0,0,0)$ & $\begin{array}{c}0.72 \\
(0.54)\end{array}$ & $\begin{array}{c}9.79 \\
(0.02)\end{array}$ \\
\hline
\end{tabular}

This table reports OLS estimates from the encompassing model,

$y_{t, t+h}=\beta_{0}+\beta_{A R} f_{t, t+h \mid t}^{A R}+\beta_{S P F} f_{t, t+h \mid t}^{S P F}+\beta_{1} D_{1984: 3}+\beta_{A R, 1}\left(D_{1984: 3} \times f_{t, t+h \mid t}^{A R}\right)+\beta_{S P F, 1}\left(D_{1984: 3} \times f_{t, t+h \mid t}^{S P F}\right)+\eta_{t, t+h}$. Newey-West (1987) standard errors are reported in parentheses under the parameter estimates. The left column reports results using quarterly real output forecasts and the right column presents estimates using annual forecasts. The last three rows present a set of Wald statistics. The first statistic tests the hypothesis that the SPF forecasts are rational and encompass the AR(1) forecasts both ptre- and postmoderation. The second statistic tests whether the SPF forecasts are rational and encompass the AR(1) forecasts prior to the Great Moderation. The last statistic tests whether there is any difference between the encompassing parameters before and after the Great Moderation. The asymptotic p-value of each test is reported in parentheses under the value of the statistic. 
Table 2

RMSE of Quarterly and Annual Real output Forecasts 1969-2002

$\underline{\text { Pre-Moderation (0) }} \quad$ Post-Moderation (1) $\quad \frac{R M S E_{1}}{R M S E_{0}}$

\section{Quarterly Forecasts}

$\begin{array}{llll}\text { SPF } & 3.98 & 2.13 & 0.54 \\ \text { AR(1) } & 4.58 & 2.04 & 0.45\end{array}$

\section{Annual Forecasts}

$\underline{\text { Pooled Sample }}$

SPF

$\operatorname{AR}(1)$

$\underline{\text { First Quarter }}$

SPF

$\operatorname{AR}(1)$

Second Quarter

SPF

$\operatorname{AR}(1)$

Third Quarter

SPF

$\operatorname{AR}(1)$

Fourth Quarter

SPF

$\operatorname{AR}(1)$

This tab from both the SPF and AR(1) model between 1969 and 2002. The results for the annual forecast data are reported together (pooled) and separately. All numbers are reported in annual percentage terms.

0.45 
Table 3

GMM Estimates of A Restricted Variance Model of Real output Forecasts and Residuals 1969:1 - 2002:2

\begin{tabular}{|c|c|c|c|c|c|c|}
\hline \multirow{3}{*}{ Quarterly Fore } & $\alpha$ & $\rho$ & $\sigma_{0, A R}$ & $\sigma_{0, S P F}$ & $\kappa$ & J-Statistic \\
\hline & & & & & & \\
\hline & $\begin{array}{c}2.08 \\
(0.69)\end{array}$ & $\begin{array}{c}0.29 \\
(0.10)\end{array}$ & $\begin{array}{c}4.45 \\
(1.94)\end{array}$ & $\begin{array}{c}4.12 \\
(1.04)\end{array}$ & $\begin{array}{l}-0.76 \\
(0.05)\end{array}$ & $\begin{array}{c}4.54 \\
(0.03)\end{array}$ \\
\hline \multicolumn{7}{|c|}{ Annual Forecasts } \\
\hline$\underline{\text { Pooled Sample }}$ & $\begin{array}{c}2.50 \\
(0.49)\end{array}$ & $\begin{array}{c}0.05 \\
(0.09)\end{array}$ & $\begin{array}{c}3.20 \\
(0.68)\end{array}$ & $\begin{array}{c}2.87 \\
(0.74)\end{array}$ & $\begin{array}{c}-0.76 \\
(0.07)\end{array}$ & $\begin{array}{c}3.47 \\
(0.06)\end{array}$ \\
\hline$\underline{\text { First Quarter }}$ & $\begin{array}{c}2.77 \\
(0.55)\end{array}$ & $\begin{array}{c}0.03 \\
(0.09)\end{array}$ & $\begin{array}{c}3.17 \\
(1.05)\end{array}$ & $\begin{array}{c}2.91 \\
(0.81)\end{array}$ & $\begin{array}{l}-0.78 \\
(0.09)\end{array}$ & $\begin{array}{c}1.90 \\
(0.17)\end{array}$ \\
\hline Second Quarter & $\begin{array}{c}2.52 \\
(0.42)\end{array}$ & $\begin{array}{c}0.09 \\
(0.08)\end{array}$ & $\begin{array}{c}3.14 \\
(0.65)\end{array}$ & $\begin{array}{c}2.78 \\
(0.84)\end{array}$ & $\begin{array}{l}-0.77 \\
(0.08)\end{array}$ & $\begin{array}{c}2.97 \\
(0.08)\end{array}$ \\
\hline Third Quarter & $\begin{array}{c}2.99 \\
(0.45)\end{array}$ & $\begin{array}{l}-0.02 \\
(0.12)\end{array}$ & $\begin{array}{c}3.11 \\
(0.84)\end{array}$ & $\begin{array}{c}2.78 \\
(1.18)\end{array}$ & $\begin{array}{l}-0.79 \\
(0.07)\end{array}$ & $\begin{array}{c}0.66 \\
(0.42)\end{array}$ \\
\hline Fourth Quarter & $\begin{array}{c}2.80 \\
(0.48)\end{array}$ & $\begin{array}{c}0.11 \\
(0.11)\end{array}$ & $\begin{array}{c}2.89 \\
(0.75)\end{array}$ & $\begin{array}{c}2.39 \\
(1.09)\end{array}$ & $\begin{array}{l}-0.78 \\
(0.08)\end{array}$ & $\begin{array}{c}2.57 \\
(0.11)\end{array}$ \\
\hline
\end{tabular}

This table reports GMM estimates from the model, $y_{t}=\alpha+\rho y_{t-1}+\varepsilon_{t}, E\left(\varepsilon^{2} \mid \Omega_{t-1}\right)=\sigma_{0, A R}^{2}\left(1+\kappa D_{t}\right), E\left(e_{t}^{2} \mid \Omega_{t-1}\right)=\sigma_{0, S P F}^{2}\left(1+\kappa D_{t}\right)$. Asymptotic standard errors are reported in parentheses under the parameter estimates. The model is estimated separately for the annual forecasts of each quarter within the year as well as a pooled sample which imposes parameter constancy across forecasts generated in different quarters. The last column of the table reports the test of the model's overidentifying restrictions and has an asymptotic $\chi^{2}(1)$ distribution. The asymptotic p-value of this test is reported in parentheses under the value of the J-statistic. A Newey-West, HAC weighting matrix was used in model estimation. 
Table 4

Information Content of SPF Recession Probability Forecasts

1968:4 - 2002:4

Quarterly

1969:2 - 2002:2

Encompassing Regression

$\beta_{0}$

0.05

$(0.27)$

$\beta_{A R}$

$-0.17$

(0.62)

$\beta_{S P F}$

0.95

$(0.27)$

$\beta_{1}$

$\beta_{A R, 1}$

1.00

(1.27)

$\beta_{S P F, 1}$

$-0.45$

(0.50)

Wald Statistic

$\left(\beta_{0}, \beta_{A R}, \beta_{S P F}, \beta_{1}, \beta_{A R, 1}, \beta_{S P F, 1}\right)=(0,0,1,0,0,0)$

The top panel of this table reports estimates from the encompassing model,

$1\left(y_{t, t+1}<0\right)=\beta_{0}+\beta_{A R} P_{t}^{A R}+\beta_{S P F} P_{t}^{S P F}+\beta_{1} D_{1984: 3}+\beta_{A R, 1}\left(D_{1984: 3} \times P_{t}^{A R}\right)+\beta_{S P F, 1}\left(D_{1984: 3} \times P_{t}^{S P F}\right)+\eta_{t, t+h}$, where $1\left(y_{t, t+1}<0\right)$ represents the event that quarterly real output growth is negative, $P_{t}^{S P F}$ is the median probability of a decline in real output growth one quarter ahead reported in the SPF, $P_{t}^{A R}$ is the probability of a decline in real output one quarter ahead computed from the Gaussian AR(1) model and $D_{1984: 3}$ is a dummy variable that takes the value one after 1984:3. The model is estimated vis-a-vis GLS by imposing the null hypothesis that the SPF forecasts represent rational forecasts of the probability of a decline in real output. Asymptotic standard errors are reported in parentheses under the parameter estimates. The Wald test of the null hypothesis that the SPF probability forecast is both rational and encompasses the AR(1) probability forecast is also presented. 
Table 5

Recession Probabilities and Uncertainty

Structural Change Before and After the Great Moderation

$\alpha$

0.24

(0.05)

0.27

$P_{t}^{A R}$

$\log \left(\frac{P_{t}^{S P F}}{1-P_{t}^{S P F}}\right)$

$\log \left(\frac{P_{t}^{A R}}{1-P_{t}^{A R}}\right)$

$-0.28$

(0.13)

$-0.72$

$\left(\alpha_{1984: 3}-\alpha\right)$

$\rho$

$\left(\rho_{1984: 3}-\rho\right)$

$\underline{\text { Recession Probability }}$

$\begin{array}{ccccc}P_{t}^{S P F} & 0.24 & -0.07 & -- & - \\ & (0.05) & (0.05) & & - \\ & & & & \\ P_{t}^{A R} & 0.27 & -0.19 & -- & \\ & (0.01) & (0.02) & & -0.12 \\ \log \left(\frac{P_{t}^{S P F}}{1-P_{t}^{S P F}}\right) & & & 0.82 & (0.10) \\ \log \left(\frac{P_{t}^{A R}}{1-P_{t}^{A R}}\right) & (0.13) & -0.25 & (0.06) & -0.08 \\ & & (0.22) & & (0.21)\end{array}$

$\underline{\text { Recession Uncertainty }}$

\begin{tabular}{rcccc}
$\sqrt{P_{t}^{S P F}\left(1-P_{t}^{S P F}\right)}$ & 0.36 & -0.02 & -- & \\
& $(0.03)$ & $(0.03)$ & & \\
$\sqrt{P_{t}^{A R}\left(1-P_{t}^{A R}\right)}$ & 0.44 & -0.16 & & \\
& $(0.01)$ & $(0.01)$ & 0.80 & -0.15 \\
$\log \left(\sqrt{P_{t}^{S P F}\left(1-P_{t}^{S P F}\right)}\right)$ & -0.22 & -0.16 & $(0.07)$ & $(0.10)$ \\
$\log \left(\sqrt{P_{t}^{A R}\left(1-P_{t}^{A R}\right)}\right)$ & $(0.07)$ & $(0.11)$ & 0.27 & -0.10 \\
& -0.61 & -0.49 & $(0.17)$ & $(0.23)$ \\
\hline
\end{tabular}

The table above reports the estimation results from the autoregressive model, $y_{t}=\alpha+\left(\alpha_{1984: 3}-\alpha\right) D_{1984: 3}+\rho y_{t-1}+\left(\rho_{1984: 3}-\rho\right)\left(D_{1984: 3} \times y_{t-1}\right)+\varepsilon_{t}$, where $D_{1984: 3}$ is a dummy variable taking the value one after 1984:3. The dependent variable being modeled is labeled in the first column. The model is estimated by OLS between 1968:4 and 2002:4 and Newey-West (1987) standard errors are reported in parentheses under the parameter estimates. 